\title{
INFLUENCIA DE LA CONCENTRACIÓN DE Se(IV) EN LA VIABILIDAD CELULAR DURANTE EL CRECIMIENTO DE LA LEVADURA Saccharomyces cerevisiae
}

\author{
*Carmen Rodríguez Besta,c, Jesús Américo Cjuno Huanca ${ }^{\mathrm{b}}$, Mario Ceroni Galloso ${ }^{\mathrm{a}}$
}

\begin{abstract}
RESUMEN
Se estudiaron los efectos inhibitorios de la concentración de Se(IV) en la curva de crecimiento de la levadura Saccharomyces cerevisiae LALVIN RC 212, para los que se desarrollaron cuatro réplicas del recuento celular y medidas de la densidad óptica durante 72 horas de cultivo. Los datos se ajustaron al modelo de Gompertz modificado con un nivel de confianza del $95 \%$ y un coeficiente de determinación mayor a 0,90 . Se utilizó el medio líquido YEPD (pH inicial 6) sometido a $30^{\circ} \mathrm{C}$ y $200 \mathrm{rpm}$, con adición de selenito después de transcurridas 5 horas de la inoculación. Las concentraciones evaluadas fueron 2, 4, 6, 8 y $10 \mathrm{mg} \mathrm{Se}(\mathrm{IV}) / \mathrm{L}$,

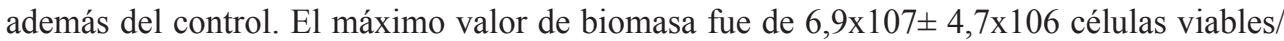
$\mathrm{mL}$ y la mayor velocidad de crecimiento de $0,646 \mathrm{~h}^{-1}$ correspondiente a la concentración de $2 \mathrm{mg} \mathrm{Se} / \mathrm{L}$ en el medio experimental. Según el ANOVA (Análisis de la Varianza), la LSD (Diferencia Mínima Significativa) y el porcentaje de células no viables, la inhibición del crecimiento de la levadura se presentó después de las 24 horas de cultivo, a las concentraciones de 6,8 y $10 \mathrm{mg} \mathrm{Se} / \mathrm{L}$. También se demostró que la determinación espectrofotométrica de $\mathrm{Se}(\mathrm{IV})$ en el medio experimental, por el método yodo-almidón ha sido factible.
\end{abstract}

Palabras clave: selenio, levadura, selenito, selenio-levadura, crecimiento celular, Gompertz, viabilidad celular.

\section{INFLUENCE OF Se(IV) CONCENTRATION ON CELULAR VIABILITY DURING YEAST Saccharomyces cerevisiae GROWTH}

\begin{abstract}
We have studied the inhibitory effect of Se(IV) concentration on Saccharomyces cerevisiae LALVIN RC 212 in 4 replicates of cell count and optic density for a 72 hours culture. Values were adjusted to the modified Gompertz model with a confidence level of $95 \%$ and a determination coefficient higher than 0,90 . We used the YEPD liquid medium $(\mathrm{pH}=6$ at

\footnotetext{
a. Unidad de Posgrado de la Facultad de Química e Ingeniería Química, Universidad Nacional Mayor de San Marcos. Lima 23, Perú,

b. Titular gerente de Fractal Químicos EIRL- www.fractalquímicos.pe

c. Laboratorio de Química Biológica y Bioanálisis. Departamento Académico de Química. Facultad de Ciencias, Universidad Nacional Agraria La Molina. carb@la molina.edu.pe
} 
the beginning) at $30{ }^{\circ} \mathrm{C}$ and $200 \mathrm{rpm}$, with added selenite 5 hours after inoculation. The analysed concentrations were 2, 4, 6, 8 y $10 \mathrm{mg} \mathrm{Se}(\mathrm{IV}) / \mathrm{L}$ and the control. The highest value of biomass was $6,9 \times 107 \pm 4,7 \times 106$ viable cells $/ \mathrm{mL}$ and the highest growth speed was $0,646 \mathrm{~h}^{-1}$, which correspond to the concentration of $2 \mathrm{mg} \mathrm{Se} / \mathrm{L}$ in the experimental medium. According to ANOVA (Analysis of Variance), LSD (Least Significance Difference) and the percentage of nonviable cells, the inhibition of yeast growth appeared 24 hours after inoculation, for the concentrations 6,8 y $10 \mathrm{mg} \mathrm{Se} / \mathrm{L}$. The feasibility of iodine-starch method for spectrophotometric determination of Se(IV) in culture was also demostrated.

Key words: selenium, yeast, selenite, selenium yeast, yeast grow, Gompertz, cellular viability

\section{INTRODUCCIÓN}

El selenio es un nutriente esencial a nivel de trazas, algunos de sus compuestos tienen propiedades antioxidantes y juegan un rol preventivo en ciertos tipos de cáncer, en humanos y animales, por eso, una dieta deficiente en selenio debe ser mejorada con el consumo de suplementos nutricionales como la selenio-levadura. La selenio-levadura o levadura selenizada, ha sido el producto natural más ampliamente investigado, una de las razones es su capacidad de suministrar formas de selenio orgánico más biodisponibles, algunas de las cuales se encuentran naturalmente en ciertos alimentos. Este producto natural se obtiene mediante el crecimiento de la levadura Saccharomyces cerevisiae en un medio de cultivo al que se adiciona selenio en forma de selenito de sodio (selenización). Las especies de selenio, que se forman durante el crecimiento, dependen de la paulatina asimilación del Se(IV) por la levadura, proceso que está influenciado por factores como: la cepa, la composición del medio de cultivo, las condiciones del cultivo y la cantidad de selenito adicionado ${ }^{1}$.

La complejidad y variabilidad de los procesos metabólicos en la levadura requieren el control de su crecimiento, que se realiza con la medida de la densidad óptica (DO), el recuento de células de levadura y el cálculo del porcentaje de células viables y no viables. La medida de la DO es una forma rápida y fácil de estimar el crecimiento de la biomasa, sin embargo, contar el número de células o determinar la viabilidad celular de la levadura también es un ensayo accesible, que permite estimar la condición de la población celular, pues una disminución en la viabilidad celular indica inhibición del crecimiento y la inducción de la respuesta al estrés, suministrando información sobre el efecto de factores en el entorno celular ${ }^{2}$. Otro aspecto de interés es conocer la concentración de Se(IV) en el medio experimental, durante el proceso de selenización. Al respecto, Kieliszek et al. utilizan, con buenos resultados, una técnica espectrofotométrica para cuantificar el Se(IV) y calcular el selenio vinculado a la biomasa de la levadura3. La técnica se basa en la siguiente reacción de óxido-reducción: $\mathrm{SeO}_{3}{ }^{2-}+4 \mathrm{I}^{-}+$ $6 \mathrm{H}^{+}{ }^{\circledR} \mathrm{Se}+2 \mathrm{I}_{2}+3 \mathrm{H}_{2} \mathrm{O}$, y el desarrollo de color se obtiene por la reacción entre la variamina azul y el yodo ${ }^{4}$, aún cuando, es factible trabajar con almidón, que forma un complejo azul con el yodo, para la misma reacción ${ }^{5}$. 
Según Brozmanová et al., mencionados por Herrero y Wellinger, la levadura Saccharomyces cerevisiae no tiene necesidad metabólica por selenio, lo que facilita el estudio de los efectos tóxicos de formas de selenio en sus funciones celulares ${ }^{6}$. En el caso del Se(IV), la cantidad presente en el medio de cultivo puede ser tóxica e inhibir el crecimiento de la levadura ${ }^{7}$, lo que justifica la evaluación de la incidencia de su concentración en la viabilidad celular. En algunos trabajos, los investigadores han estudiado aspectos relacionados al tipo de medio de cultivo, preparación y cantidad de inóculo, tipo y viabilidad de la cepa de levadura así como la forma y momento de incorporación del selenito al medio de cultivo, principalmente para concentraciones de 10 a $60 \mathrm{mg} \mathrm{Se} / \mathrm{L}^{8-11}$, aunque también se han utilizado concentraciones de 19 a $57 \mu \mathrm{M}(1,6 ; 3,1 \text { y 4,5 mg Se/L, aproximadamente) })^{7}$, todos ellos con el propósito de alcanzar la estandarización y control del mencionado proceso; sin embargo, los esfuerzos por establecer la concentración de Se(IV) adecuada para el crecimiento de la biomasa de levadura continúan.

El objetivo del presente trabajo ha sido evaluar la influencia de diferentes concentraciones de $\mathrm{Se}(\mathrm{IV})$ en la viabilidad celular de la levadura Saccharomyces cerevisiae durante el crecimiento y determinar su contenido en el medio experimental con el método espectrofotométrico yodo-almidón.

\section{PARTE EXPERIMENTAL}

\section{Material biológico}

Para la obtención de las curvas de crecimiento se ha utilizado la levadura seca activa, Lalvin RC 212 (Bourgovin, GMO and gluten free). Saccharomyces cerevisiae producida por Lallemand INC. Montreal Qc, Canada HIW 2 N8.

\section{Reactivos}

En la preparación del medio de cultivo se utilizó glucosa anhidra Fisher Scientific ACS certificada; extracto de levadura US Biological, grado biología molecular; peptona BD Bacto peptona y agua destilada.

La solución de selenito se preparó con selenito de sodio P.A. (99 \%) Panreac Appli Chem y para el recuento celular se utilizó azul de metileno Riedel de Haen para microscopía. En la preparación de las soluciones para el método yodo-almidón se utilizó HCl Baker ACS (36,5$38 \%$ ), yoduro de potasio (99 \%) Merck Emsure y almidón soluble Scharlau, además de agua destilada.

\section{Equipos}

Autoclave ALP modelo CLG-32L/40M/40L, cabina de bioseguridad Biobase modelo 11231BBC86 MSCClase II, agitadororbital ThermoScientific MAXQ7000, espectrofotómetro Biomate 3 Thermo Electron Corporation, pHmetro UB-10 Denver Instrument, microscopio Olympus modelo CX31RBSFA, cámara Neubauer- BOECO Germany, bright line, modelo Tiefe Depth. Profondeur (0.100 mm - 0.0025mm2). 


\section{Metodología}

\section{Preparación del medio de cultivo}

Tanto el medio de cultivo líquido YEPD (Yeast Extract Peptone Dextrose), que se preparó según la composición de la tabla 1, como la solución de selenito de sodio (conteniendo 1000 $\mathrm{mg} \mathrm{Se} / \mathrm{L}$ ) fueron autoclavados a $121^{\circ} \mathrm{C}$ y $16 \mathrm{lb} / \mathrm{pulg} 2$ durante 20 minutos.

Tabla 1. Composición del medio de cultivo YEPD.

\begin{tabular}{ll}
\hline COMPONENTE & $\mathrm{g} / \mathrm{L}$ \\
\hline Extracto de levadura & 10,0 \\
Peptona & 20,0 \\
Glucosa & 20,0 \\
\hline
\end{tabular}

\section{Preparación del inóculo}

Se pesó $0,011 \mathrm{~g}$ de levadura seca activa, LALVIN RC 212, que se adicionó a $50 \mathrm{~mL}$ de YEPD estéril, en un matraz erlenmeyer de $250 \mathrm{~mL}$. El matraz se colocó en baño maría a $42 \pm 1^{\circ} \mathrm{C}$ durante 15 minutos (según indicaciones del fabricante), después se retiró, se mezcló el YEPD con la levadura y se continuó con la agitación a $30^{\circ} \mathrm{C}$ y $200 \mathrm{rpm}$ durante 24 horas ${ }^{3}$.

\section{Adición de selenito}

En la cámara de bioseguridad, se adicionaron $5 \mathrm{~mL}$ de inóculo (cultivo de 24 horas de Saccharomyces cerevisiae, LALVIN RC 212 que contenía 4,5 a 5,5 x107 cel/mL) a cada matraz erlenmeyer de $250 \mathrm{~mL}$ conteniendo $45 \mathrm{~mL}$ de medio líquido YEPD autoclavado. Después de inocular, los matraces, debidamente acondicionados, se colocaron en el agitador a $30^{\circ} \mathrm{C}$ y $200 \mathrm{rpm}$. Posteriormente, se midió el pH inicial del YEPD autoclavado. Transcurridas 5 horas de crecimiento, se agregaron volúmenes de solución de selenito de sodio en todos los medios experimentales, excepto en uno (control), con el propósito de obtener concentraciones de 0 (control), 2, 4, 6, 8 y $10 \mathrm{mg} \mathrm{Se/L.} \mathrm{Posteriormente,} \mathrm{se} \mathrm{continuó} \mathrm{la} \mathrm{agitación} \mathrm{de} \mathrm{todos} \mathrm{ellos}$ a $30^{\circ} \mathrm{C}$ y $200 \mathrm{rpm}$ hasta completar 72 horas de cultivo ${ }^{3}$.

\section{Densidad óptica y viabilidad}

Se realizaron cuatro repeticiones de las mediciones de DO y de recuento celular, la DO se realizó a $600 \mathrm{~nm}$ según el procedimiento descrito por Kieliszek et al. ${ }^{3}$ y para el recuento celular se utilizó la tinción con azul de metileno, para calcular el número de células viables y no viables ${ }^{12}$ para cada una de las concentraciones de Se(IV)/L; cada hora durante 12 horas; luego cada dos horas hasta las 24 horas y finalmente cada cuatro horas hasta las 72 horas.

\section{Determinación de Se(IV) con el método yodo-almidón}

El método espectrofotométrico propuesto por Narayana et al. se basa en la reacción del selenito y el yoduro de potasio en medio ácido, que libera yodo y forma un complejo de 
color azul con el almidón, con máxima absorbancia a $570 \mathrm{~nm}$. Los estándares se prepararon en fiolas de $10 \mathrm{~mL}$, con volúmenes de la solución de trabajo de $\mathrm{Se}(\mathrm{IV}) ; 1,0 \mathrm{~mL}$ de KI al 2 $\%(\mathrm{p} / \mathrm{v}) ; 1,0 \mathrm{~mL}$ de $\mathrm{HCl} 2 \mathrm{M}$ y $0,2 \mathrm{~mL}$ de almidón al $1 \%(\mathrm{p} / \mathrm{v}) 5$. La solución stock de 1000 $\mathrm{mg} \mathrm{Se(IV)/L} \mathrm{se} \mathrm{preparó} \mathrm{con} \mathrm{selenito} \mathrm{de} \mathrm{sodio} \mathrm{y} \mathrm{luego} \mathrm{las} \mathrm{soluciones} \mathrm{de} \mathrm{trabajo} \mathrm{se} \mathrm{prepararon}$ mediante dilución de la solución stock. Se verificó el $\lambda_{\text {max }}$ con el estándar de 0,6 mg Se/L y el blanco. Después se prepararon los estándares a concentraciones de 0 a $1,0 \mu \mathrm{g} \mathrm{Se} / \mathrm{mL}$ en fiolas de $10 \mathrm{~mL}$, sin y con adición del medio YEPD $(0,5 \mathrm{~mL})$, volúmenes de la solución de trabajo de $\mathrm{Se}(\mathrm{IV}) ; 1,0 \mathrm{~mL}$ de $\mathrm{KI}$ al $2 \%(\mathrm{p} / \mathrm{v}) ; 1,0 \mathrm{~mL}$ de $\mathrm{HCl} 2 \mathrm{M}$ y $0,2 \mathrm{~mL}$ de almidón al $1 \%(\mathrm{p} / \mathrm{v})$, se llevaron a aforo con agua destilada, se homogeneizaron y las mediciones de absorbancia se realizaron a $570 \mathrm{~nm}$. La determinación de $\mathrm{Se}(\mathrm{IV})$ en la muestra se realizó en el sobrenadante del medio experimental recuperado a las 24,48 y 72 horas de cultivo para cada concentración de adicionada. Luego de centrifugar $1 \mathrm{~mL}$ del medio a $5000 \mathrm{rpm}$ x 5 minutos durante la medida de la DO, se decanta, filtra y mide $0,5 \mathrm{~mL}$ que se adiciona a fiolas de 10 $\mathrm{mL}$; posteriormente, se adiciona $1,0 \mathrm{~mL}$ de $\mathrm{KI}$ al $2 \%(\mathrm{p} / \mathrm{v}) ; 1,0 \mathrm{~mL}$ de $\mathrm{HCl} 2 \mathrm{M}$ y $0,2 \mathrm{~mL}$ de almidón al 1\%(p/v), se lleva a aforo, se homogeneiza y mide a $570 \mathrm{~nm}$.

\section{Pruebas estadísticas}

La evaluación de la cinética de crecimiento de la levadura se realizó utilizando el modelo matemático de Gompertz ${ }^{13}$. El modelamiento matemático se realizó con un nivel e confianza del $95 \%$ teniendo en cuenta el coeficiente de determinación $\mathrm{R}^{2}(>0,90)$. Se utilizó el paquete estadístico R 3.2.5, con los paquetes: "nls2" y "proto".

\section{RESULTADOS Y DISCUSIÓN}

\section{Modelamiento de las curvas de crecimiento}

Las cuatro réplicas de mediciones de DO (31 por réplica) y recuento de células viables (31 por réplica) de la levadura Saccharomyces cerevisiae LALVIN RC 212, para cada concentración de $\operatorname{Se}(\mathrm{IV})(0,2,4,6,8$ y $10 \mathrm{mg} / \mathrm{L})$, en el medio experimental YEPD, a pH inicial de 6 , a $30^{\circ} \mathrm{C}$ y $200 \mathrm{rpm}$ durante 72 horas, permitieron el ajuste al modelo de Gompertz modificado, con la ecuación: $\mathbf{Y}=\mathbf{a} * \exp \left(-\exp \left(\mathbf{b}-\mathbf{c}^{*} \mathbf{T}\right)\right.$, donde a corresponde al máximo valor de biomasa (cel/ $\mathrm{mL})$, b es la velocidad de crecimiento respecto al tiempo $[(\log (\mathrm{cel} / \mathrm{mL}) / \mathrm{h}]$ y c es el tiempo requerido para alcanzar la máxima velocidad (horas). Todos los coeficientes hallados en el modelamiento $(\mathbf{a}, \mathbf{b} \mathbf{y} \mathbf{c})$ fueron significativos $(\mathrm{p}<0,05)$ para cada concentración de selenio. Los coeficientes de determinación $\left(\mathrm{R}^{2}\right)$ fueron superiores a 0,90 para todas y cada una de las concentraciones de Se(IV) y la prueba de Shapiro-Wilk mostró que los residuales cumplen con distribuirse normalmente para cada una de las concentraciones de Se (IV), 0, 2, 4, 6, 8 y $10 \mathrm{mg} / \mathrm{L}$.

A partir de los coeficientes se generaron los valores de las curvas de crecimiento de las figuras 1 y 2. En la figura 1 se aprecia que el número de células viables (en unidades logarítmicas) es mayor en el medio que contenía $2 \mathrm{mg}$ Se/L que en las demás concentraciones $(4,6,8$, $10 \mathrm{mg} \mathrm{Se} / \mathrm{L}$ ), incluso mayor que en el control; mientras que para la figura 2 el mayor valor de DO (unidades logarítmicas) corresponde al medio con $10 \mathrm{mg} \mathrm{Se} / \mathrm{L}$, aunque se observa 
una mayor cercanía a los valores de las demás concentraciones (2, 4, 6, $8 \mathrm{mg} \mathrm{Se} / \mathrm{L})$. La explicación de los diferentes comportamientos en cada figura se relaciona con la naturaleza de las mediciones, en el primer caso se tiene la curva de crecimiento en función de las células viables de la levadura, y en el otro la medida de la DO corresponde a la turbidez producida por el número total de células de levadura (viables y no viables).

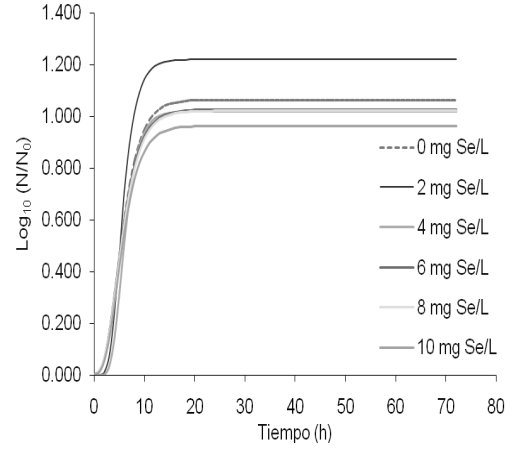

Figura 1. Curva de crecimiento de la levadura Saccharomyces cerevisiae LALVIN RC 212, según el modelo Gompertz modificado en función del número de células viables/mL.

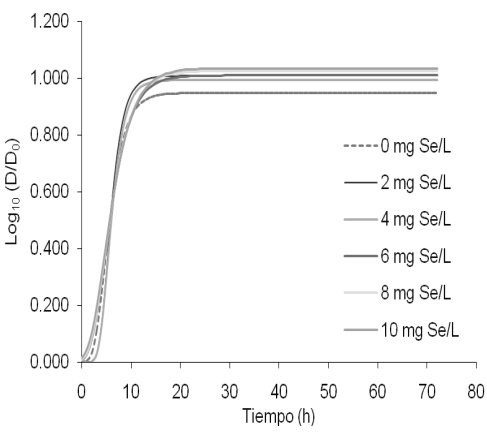

Figura 2. Curva de crecimiento de la levadura Saccharomyces cerevisiae LALVIN RC 212, según el modelo Gompertz modificado en función de la DO.

Según los parámetros cinéticos que se aprecian en la tabla 2, el máximo valor de biomasa de $6,9 \times 10^{7} \pm 4,7 \times 10^{6}$ células viables $/ \mathrm{mL}$ y la mayor velocidad de crecimiento de $0,646 \mathrm{~h}^{-1}$ corresponden a la concentración de $2 \mathrm{mg} \mathrm{Se} / \mathrm{L}$ en el medio experimental y el menor tiempo de latencia se presenta para la concentración de $10 \mathrm{mg} \mathrm{Se} / \mathrm{L}$. Este comportamiento para los valores de biomasa y velocidad de crecimiento se explican porque al ingresar el selenio a las células de $S$. cerevisiae, e interferir con los procesos celulares, también puede producirse la activación de rutas metabólicas requeridas para la desintoxicación y tolerancia al selenio ${ }^{6}$, por tal razón, se logran mayores valores con la menor concentración. Por otro lado, en el caso de la latencia, la concentración de Se(IV) en el medio experimental no influye en la viabilidad, pues la adición de selenito de sodio se realizó a las cinco horas de la inoculación.

Tabla 2. Parámetros cinéticos del recuento de células viables.

\begin{tabular}{|c|c|c|c|c|}
\hline $\begin{array}{r}\mathrm{mg} \\
\mathrm{Se} / \mathrm{L}\end{array}$ & $\begin{array}{l}\text { Valor máximo de } \\
\text { biomasa (a) } \\
(\text { cel/mL) }\end{array}$ & $\begin{array}{c}\text { Tiempo de } \\
\text { latencia }(\lambda)[h]\end{array}$ & $\begin{array}{c}\text { Velocidad } \\
\text { específica de } \\
\text { crecimiento } \mu \\
\left(\mathbf{h}^{-1}\right)\end{array}$ & $\begin{array}{c}\text { Tiempo de } \\
\text { generación } \mathbf{G} \\
\text { (h) }\end{array}$ \\
\hline 0 & $5,0 \mathrm{E}+07 \pm 1,6 \mathrm{E}+07$ & $2,041 \pm 0,385$ & $0,430 \pm 0,076$ & $1,654 \pm 0,315$ \\
\hline 2 & $6,9 \mathrm{E}+07 \pm 4,7 \mathrm{E}+06$ & $2,743 \pm 1,288$ & $0,646 \pm 0,143$ & $1,114 \pm 0,246$ \\
\hline 4 & $4,7 \mathrm{E}+07 \pm 2,0 \mathrm{E}+07$ & $3,102 \pm 1,535$ & $0,525 \pm 0,053$ & $1,331 \pm 0,134$ \\
\hline 6 & $4,7 \mathrm{E}+07 \pm 1,9 \mathrm{E}+07$ & $2,021 \pm 0,475$ & $0,422 \pm 0,085$ & $1,696 \pm 0,341$ \\
\hline 8 & $4,6 \mathrm{E}+07 \pm 1,7 \mathrm{E}+07$ & $1,988 \pm 0,433$ & $0,410 \pm 0,077$ & $1,737 \pm 0,336$ \\
\hline 10 & $4,3 \mathrm{E}+07 \pm 2,3 \mathrm{E}+07$ & $1,974 \pm 0,921$ & $0,393 \pm 0,120$ & $1,953 \pm 0,830$ \\
\hline
\end{tabular}


En la tabla 3 se muestran los parámetros cinéticos de DO, donde el máximo valor de biomasa de $0,976 \pm 0,096$ y el menor tiempo de latencia de $0,745 \pm 2,237$ corresponden a $10 \mathrm{mg}$ $\mathrm{Se} / \mathrm{L}$, no obstante que la mayor velocidad específica de crecimiento y el menor tiempo de generación corresponden a la concentración de $2 \mathrm{mg} \mathrm{Se} / \mathrm{L}$, comportamiento que coincide con el encontrado en función de la viabilidad celular.

Tabla 3. Parámetros cinéticos de densidad óptica.

\begin{tabular}{ccccccc}
\hline $\begin{array}{c}\mathbf{m g} \\
\mathbf{S e} / \mathbf{L}\end{array}$ & $\begin{array}{c}\text { Valor máximo de } \\
\text { biomasa } \\
\text { (densidad óptica) }\end{array}$ & $\begin{array}{c}\text { Tiempo de } \\
\text { latencia }(\boldsymbol{\lambda})[\mathbf{h}]\end{array}$ & $\begin{array}{c}\text { Velocidad } \\
\text { específica de } \\
\text { crecimiento } \boldsymbol{\mu} \\
\left(\mathbf{h}^{-1}\right)\end{array}$ & $\begin{array}{c}\text { Tiempo de } \\
\text { generación G } \\
\mathbf{( h )}\end{array}$ \\
\hline 0 & $0,796 \pm 0,036$ & $2,408 \pm 0,523$ & $0,431 \pm 0,098$ & $1,667 \pm 0,352$ \\
2 & $0,918 \pm 0,091$ & $3,308 \pm 0,898$ & $0,567 \pm 0,094$ & $1,248 \pm 0,215$ \\
4 & $0,890 \pm 0,134$ & $3,322 \pm 0,989$ & $0,547 \pm 0,108$ & $1,300 \pm 0,216$ \\
6 & $0,921 \pm 0,102$ & $0,860 \pm 2,794$ & $0,348 \pm 0,160$ & $2,743 \pm \pm 2,214$ \\
8 & $0,954 \pm 0,087$ & $0,989 \pm 2,371$ & $0,346 \pm 0,152$ & $2,593 \pm 1,836$ \\
10 & $0,976 \pm 0,096$ & $0,745 \pm 2,237$ & $0,330 \pm 0,155$ & $2,743 \pm 1,909$ \\
\hline
\end{tabular}

Al aplicar el estadístico de Levene a las mediciones de DO, todos los parámetros: valor máximo de biomasa, tiempo de latencia, velocidad específica de crecimiento y tiempo de generación, cumplen con la homogeneidad de varianzas $(\mathrm{p}>005)$, mientras que de los parámetros para viabilidad celular, sólo la velocidad específica de crecimiento y el tiempo de generación cumplen con la homogeneidad de varianza. Es probable que la estimación del valor máximo de biomasa y el tiempo de latencia, en función del recuento de células viables, no cumplan con la homogeneidad, porque para estimar la condición de la población de levadura, se requiere de la actividad reductora de las células de levadura, que son las que transforman el azul de metileno en su forma incolora, mientras las células muertas (no viables) se tiñen de azul ${ }^{12}$.

En el ANOVA (Análisis de la Varianza) se encontraron diferencias significativas en el valor máximo de biomasa, el tiempo de latencia y la velocidad específica de crecimiento, para las diferentes concentraciones de selenio en el caso de viabilidad celular. Para la DO no hay evidencia suficiente para determinar efecto significativo. La prueba de LSD (Diferencia

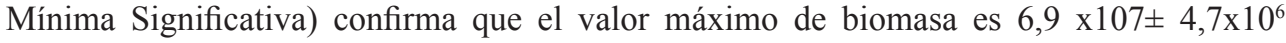
células/mL y el valor más alto de velocidad específica de crecimiento, corresponden a un contenido de $2 \mathrm{mg}$ de Se (IV)/L en el medio experimental, y el menor tiempo de latencia se presenta para las concentraciones de 6,8 y $10 \mathrm{mg} \mathrm{Se}(\mathrm{IV}) / \mathrm{L}$.

Respecto a los resultados obtenidos para el porcentaje de células no viables, como se aprecia en la tabla 4, se incrementa en función del tiempo y conforme es mayor la concentración de $\mathrm{Se}(\mathrm{IV})$ en el medio de cultivo. Las concentraciones de 4, 6, 8 y $10 \mathrm{mg} \mathrm{Se(IV)/L} \mathrm{tienen}$ un porcentaje igual o superior al $10 \%$ después de las 48 horas de cultivo y las biomasas cultivadas durante 72 horas presentaron color rosado para las concentraciones de 6,8 y $10 \mathrm{mg}$ $\mathrm{Se}(\mathrm{IV}) / \mathrm{L}$. Por eso, Marinescu y Stoicescu mencionan que el color de los productos de selenio- 
levadura dependen del contenido de selenio, así, los productos con bajo contenido, exhiben un color crema, con contenido medio color rosado y para aquellos con alto contenido color rojo ${ }^{11}$. Este comportamiento también coincide con lo descrito en una reciente investigación, donde se explica que la coloración rojiza en la biomasa celular ocurre por los procesos de desintoxicación realizados por la levadura ${ }^{14}$.

Según los estudios realizados, los compuestos inorgánicos de selenio, como el selenito, pueden ser metabolizados dentro de la célula, en un proceso que involucra al glutatión reducido (GSH) con la consiguiente formación de glutatión oxidado (GSSG) y las especies de oxígeno reactivo (ROS) ${ }^{6}$. Entonces, el selenito cambia la relación GSH: GSSG, mediante la oxidación del GSH, inhibiendo fases de la división celular y síntesis de proteínas, afectando las enzimas, pudiendo causar daño al DNA e inducir apoptosis7, lo que se refleja en los mayores incrementos de los porcentajes de células no viables en las concentraciones de 6,8 y $10 \mathrm{mg} \mathrm{Se}(\mathrm{IV}) / \mathrm{L}$, con valores cercanos al $30 \%$ para $10 \mathrm{mg} \mathrm{Se} / \mathrm{L}$ a las 72 horas de cultivo $(28,9 \%)$.

Tabla 4. Porcentaje de células no viables en función del tiempo y la concentración de $\mathrm{Se}(\mathrm{IV})$ en el medio experimental.

\begin{tabular}{|c|c|c|c|c|c|c|}
\hline $\begin{array}{l}\text { Tiempo } \\
\text { (horas) }\end{array}$ & & & $\begin{array}{c}\% \mathrm{de} \\
\text { Células No } \\
\text { Viables }\end{array}$ & & & \\
\hline & $0 \mathrm{mg} \mathrm{Se} / \mathrm{L}$ & $2 \mathrm{mg} \mathrm{Se} / \mathrm{L}$ & $4 \mathrm{mg} \mathrm{Se} / \mathrm{L}$ & $6 \mathrm{mg} \mathrm{Se} / \mathrm{L}$ & $8 \mathrm{mg} \mathrm{Se} / \mathrm{L}$ & $10 \mathrm{mg} \mathrm{Se} / \mathrm{L}$ \\
\hline 28 & 0,9 & 1,9 & 1,4 & 2,2 & 3,1 & 3,4 \\
\hline 32 & 2,1 & 4,0 & 4,5 & 6,0 & 6,0 & 7,0 \\
\hline 36 & 4,0 & 5,0 & 4,0 & 8,3 & 7,5 & 11,0 \\
\hline 40 & 4,1 & 5,4 & 6,4 & 10,0 & 9,0 & 12,5 \\
\hline 44 & 4,7 & 5,7 & 7,7 & 13,9 & 10,0 & 13,6 \\
\hline 48 & 8,5 & 5,7 & 10,1 & 14,2 & 10,3 & 14,4 \\
\hline 52 & 8,6 & 8,9 & 13,4 & 14,1 & 11,4 & 21,5 \\
\hline 56 & 10,3 & 10,1 & 17,5 & 14,7 & 13,6 & 19,7 \\
\hline 60 & 10,9 & 12,2 & 16,8 & 15,0 & 15,3 & 20,7 \\
\hline 64 & 11,5 & 11,7 & 16,8 & 18,4 & 18,0 & 22,3 \\
\hline 68 & 12,5 & 12,9 & 16,7 & 20,1 & 16,9 & 25,2 \\
\hline 72 & 13,3 & 12,4 & 18,0 & 22,7 & 24,1 & 28,9 \\
\hline
\end{tabular}

\section{Determinación de $\mathrm{Se}(\mathrm{IV})$ en el medio experimental}

El espectro de absorción para el método yodo-almidón permitió confirmar la longitud de onda de trabajo a $570 \mathrm{~nm}$. La ecuación de la curva de calibración dio y $=0,7611 \mathrm{x}+0,1856$ con $\mathrm{R}^{2}=0,9989$ y las pruebas de recuperación con estándares de 0,$4 ; 0,6$ y $0,8 \mu \mathrm{g} \mathrm{Se}(\mathrm{IV}) /$ $\mathrm{mL}$, para 4 repeticiones dieron valores de $98,90 \pm 0,30 \% ; 99,30 \pm 0,20 \%$ y $99,07 \pm 0,33 \%$, respectivamente.

Las curvas de calibración con la adición de YEPD fueron $\mathrm{y}=0,6898 \mathrm{x}+0,0054$ con un R2 de 0,9998 cuando se adiciona $0,5 \mathrm{~mL}$ de YEPD estéril para un rango de concentraciones de 0 a $1,0 \mu \mathrm{g} \mathrm{Se}(\mathrm{IV}) / \mathrm{mL}$, como se observa en la figura 3 y cuando se adicionó $0,5 \mathrm{~mL}$ de YEPD (después de 72 horas de cultivo), se obtuvo la ecuación $\mathrm{y}=0,608 \mathrm{x}$ con un $\mathrm{R} 2=0,9999$ para 
un rango de concentraciones de 0 a 1,2 $\mu \mathrm{g} \mathrm{Se}(\mathrm{IV}) / \mathrm{mL}$ (figura 4); sin embargo, las pruebas de recuperación dieron valores inferiores a $98 \%$. Aunque los valores de los coeficientes de Pearson se aproximan a 1, para ambas ecuaciones, es evidente que los componentes del medio YEPD se modifican durante el cultivo de la levadura Saccharomyces cerevisiae Lalvin RC 212, en las diferentes etapas de crecimiento (latencia, logarítmica, estacionaria, letal). Este comportamiento indica que el efecto matriz del medio estéril es diferente de aquel después de la inoculación. Al aplicar el método espectrofotométrico yodo-almidón a las muestras de los medios experimentales, sólo se logró cuantificar el selenio en el medio que contenía 10 $\mathrm{mg} \mathrm{Se} / \mathrm{L}$ inicialmente, con valores de $6,8 \mathrm{mg} \mathrm{Se} / \mathrm{L}$ a las 24 horas; 4,6 mg Se/L a las 48 horas y 3,0 mg Se/L a las 72 horas de cultivo, lo que implica una incorporación de $70 \%$ del Se(IV) a la biomasa de levadura, durante 67 horas desde la adición del selenito al medio de cultivo.

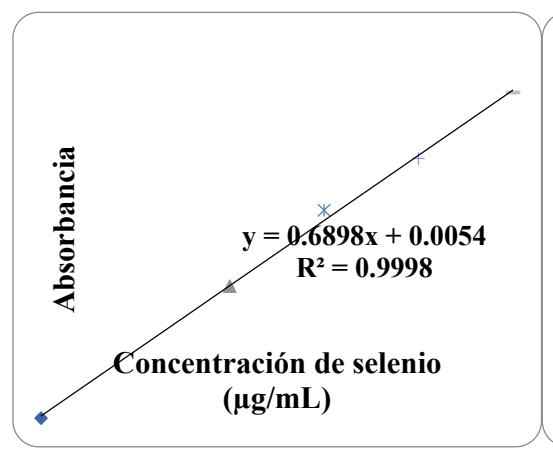

Figura 3. Curva estándar de Se(IV) a 570 $\mathrm{nm}$ en presencia de medio YEPD estéril.

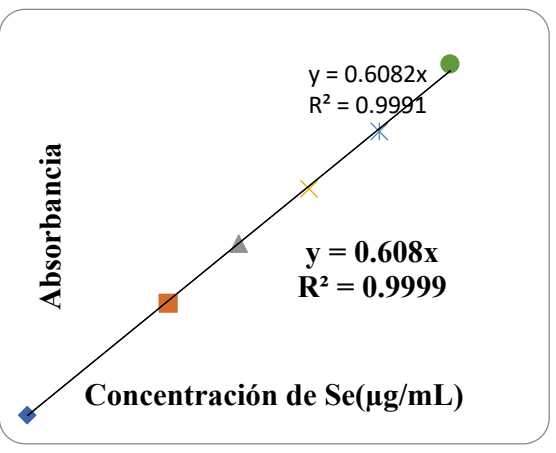

Figura 4. Curva estándar de Se(IV) a 570 $\mathrm{nm}$ en presencia de medio YEPD de 72 hrs de cultivo.

Considerando los resultados del modelamiento realizado, del ANOVA, la LSD y el porcentaje de células no viables, las concentraciones de 6, 8 y $10 \mathrm{mg} \mathrm{Se(IV)/L} \mathrm{en} \mathrm{el} \mathrm{medio} \mathrm{de} \mathrm{cultivo}$ YEPD en las condiciones mencionadas, inhiben el crecimiento de la levadura Saccharomyces cerevisiae LALVIN RC 212.

\section{CONCLUSIONES}

Las medidas de DO y número de células viables $/ \mathrm{mL}$ permite modelar el crecimiento de la levadura Saccharomyces cerevisiae Lalvin RC 212, según el modelo de Gompertz modificado, en el medio YEPD a un $\mathrm{pH}$ inicial de 6 , a $30^{\circ} \mathrm{C}$ y $200 \mathrm{rpm}$, por un periodo de 72 horas. El análisis estadístico indica que hay evidencia de diferencia significativa en los valores de viabilidad celular para la concentración de $2 \mathrm{mg} \mathrm{Se}(\mathrm{IV})$ respecto a las de 0 , 4, 6,8 y $10 \mathrm{mg}$ de Se(IV). La inhibición del crecimiento de la levadura se presenta después de las 24 horas de cultivo, como pérdida de viabilidad o mayor porcentaje de células no viables, a las concentraciones de 6,8 y $10 \mathrm{mg}$ Se/L. Además, es factible la determinación espectrofotométrica de Se(IV) en el medio experimental, por el método yodo-almidón aunque deben mejorarse aspectos de la cuantificación. 


\section{AGRADECIMIENTO}

Los autores expresan su agradecimiento a la $\mathrm{PhD}$ Gretty Villena Chávez, Directora del Laboratorio de Micología y Biotecnología "Marcel Gutiérrez Correa", por las facilidades brindadas para la ejecución de ensayos de cultivo y recuento de levaduras. Al Vicerrectorado de Investigación de la Universidad Nacional Agraria La Molina, en el marco del Convenio MINEDU-UNALM 2017, por el financiamiento otorgado para el desarrollo de la presente investigación.

\section{REFERENCIAS BIBLIOGRÁFICAS}

1. Kieliszek M, Blazejak S, Gientka L, Bzducha-Wrobel A. Accumulation and metabolism of selenium by yeast cells. Appl Microbiol Biotechnol. 2015; 99: 5373-5382.

2. Jamnik P, Raspor P. Methods for Monitoring Oxidative Stress Response in Yeasts. J Biochem Mol Toxicol. 2005; 19 (4): 195-203.

3. Kieliszek M, Blazejak S, Placzek M. Spectrophotometric evaluation of selenium binding by Saccharomyces cerevisiae ATCC MYA-2200 and Candida utilis ATCC9950 yeast. J Trace Elem Med Biol. 2016; 35: 90-96.

4. Revanasiddappa HD, Kiran Kumar TN. A Facile Spectrophotometric Method for the Determination of Selenium. Anal Sci. 2001; 17:1309-1312.

5. Narayana B, Mathew M, Bhat NG, Sreekumar NV. Spectrophotometric Determination of Selenium Using Potassium Iodide and Starch as Reagents. Microchim Acta. 2003; 141:175-178.

6. Herrero E, Wellinger RE. Yeast as a model system to study metabolic impact of selenium compounds. Microb Cell. 2015; 2 (5): 139-149.

7. Kaur T, Bansal MP. Selenium enrichment and anti-oxidant status in baker's yeast, Saccharomyces cerevisiae at different sodium selenite concentrations. Nutr Hosp. 2006; 21(6): 704-708.

8. Rajashree K, Muthukumar T. Selection of culture medium and conditions for the production of selenium enriched Saccharomyces cerevisiae. Afr J Biotechnol. 2013; 12(20): 2972- 2977.

9. Ponce de León CA, Bayón MM, Paquin C, Caruso JA. Selenium incorporation into Saccharomyces cells: a study of different incorporation methods. J Appl Microbiol. 2002; 92: 602-610.

10. Suhajda Á, Hegóczki J, Janzsó B, Pais I, Vereczkey G. Preparation of selenium yeasts. I Preparation of selenium-enriched Saccharomyces cerevisiae. J Trace Elem Med Biol. 2000; 14:43-47.

11. Marinescu G, Stoicescu AG. Industrial nutrient medium use for yeast selenium preparation. AUDJG- Food Technology. 2011; 35(1):45-53.

12. Castelucci F. Análisis microbiológico del vino y del mosto: Recuento de células de levadura-tinción de células de levadura con azul de metileno. [Internet] Resolución OIV/OENO 206/2010. [actualizado 21 mayo 2018]. Disponible en: http://www.oiv.int/ public/medias/ 1245/oiv-oeno-206-2010-es.pdf. 
13. Aguilar J, Espinoza M, Cabanillas J, Avila I, García A, Julca J et al. Evaluación de la cinética de crecimiento de Saccharomyces cerevisiae utilizando un medio de cultivo a base de melaza de caña y suero lácteo. Agroind Sci. 2015; 5(1):37-47.

14. Kieliszek M, Blazejak S, Kurek E. Binding and Conversion of Selenium in Candida utilis ATCC 9950 Yeasts in Bioreactor Culture. Molecules. 2017 Feb 25; 22(3). pii: E352. doi: 10.3390/molecules22030352. 